\title{
REACTIVE BIMOLECULAR COLLISIONS STUDIED WITH COMBINED PULSED LASERS AND PULSED, CROSSED, SUPERSONIC MOLECULAR BEAMS
}

\author{
M. COSTES, C. NAULIN, G. DORTHE and Z. MOUDDEN \\ URA 348 CNRS: Photophysique et Photochimie Moléculaire $\dagger$ Université \\ Bordeaux I, 33405 Talence cedex, France
}

(Received March 30, 1990; in final form April 30, 1990)

\begin{abstract}
Pulsed, supersonic molecular beams and pulsed lasers are particularly well matched tools when combined in molecular reaction dynamics studies. Salient features of an experiment using two pulsed molecular beam sources, a pulsed ultra-violet laser for creating reactive atoms by laser ablation and a pulsed dye laser for performing laser-induced fluorescence detection of the products are described. Differences with steady-state molecular beam experiments are outlined with respect to the following points: facility of inverting the data, possibility of obtaining high signal-to-background ratios and wide ranges of collision energy. These points are illustrated with some results concerning the reactions: $\mathrm{C}\left({ }^{3} \mathrm{P}_{\mathrm{J}}\right)+\mathrm{NO}\left(\mathrm{X}^{2} \pi_{\mathrm{r}}\right)$ $\rightarrow \mathrm{CN}\left(\mathrm{X}^{2} \Sigma^{+}\right)+\mathrm{O}\left({ }^{3} \mathrm{P}_{\mathrm{J}}\right), \mathrm{C}\left({ }^{3} \mathrm{P}_{\mathrm{J}}\right)+\mathrm{N}_{2} \mathrm{O}\left(\mathrm{X}^{1} \Sigma^{+}\right) \rightarrow \mathrm{CN}\left(\mathrm{X}^{2} \Sigma^{+}\right)+\mathrm{NO}\left(\mathrm{X}^{2} \pi_{\mathrm{r}}\right)$ and $\mathrm{Mg}\left({ }^{1} \mathrm{~S}_{0}\right)+\mathrm{N}_{2} \mathrm{O}\left(\mathrm{X}^{1} \Sigma^{+}\right)$ $\rightarrow \operatorname{MgO}\left(\mathrm{X}^{1} \Sigma^{+}\right)+\mathrm{N}_{2}\left(\mathrm{X}^{1} \Sigma_{\mathrm{g}}{ }^{+}\right)$.
\end{abstract}

KEY WORDS: Pulsed lasers, laser ablation, laser-induced fluorescence, pulsed supersonic molecular beams, reactive scattering.

About ten years ago, it was stressed that bimolecular inelastic scattering experiments gained substantial advantages when performed with supersonic molecular beam sources, delivering pulses of very short duration and high peak intensity ${ }^{1-3}$ In particular, the most severe limitation encountered in crossed, continuous molecular beam scattering studies, the signal versus background problem, was virtually eliminated due to higher instantaneous molecular beam intensities, which are not limited by differential pumping requirements, and time-of-flight discrimination of the background signal. Another major advantage of pulsed molecular beam sources suggested at that time, which became fully justified afterwards, was their facile interfacing with powerful pulsed ultra-violet lasers for generating high fluxes of reactive chemical species.

By laser photolysis of a stable precursor molecule, or by laser ablation of a solid target, many interesting reactive species, including free radicals and atoms, could be produced. Moreover, by focussing the laser beam in the hydrodynamic region or in the free molecular region of the pulsed molecular flow, or by varying the delay between the pulsed valve and the pulsed laser triggering, various degrees of cooling

† And GDR 87 CNRS: Dynamique des Réactions Moléculaires. 
of the translational and internal degrees of freedom of the reactive species of interest could be obtained. ${ }^{4}$ Finally, other exotic species could be synthetised by laserinduced chemical processes resulting from interactions of photolysed or photoablated products with reactive gases in the hydrodynamic region.

The highly efficient pulsed valve-pulsed ultra-violet laser combination launched reactive scattering experiments which could hardly have been performed by using the conventional continuous molecular beam approach. The first reaction dynamics studies of this new type were performed in our laboratory using the laser ablation technique for generating beams of ground state $\mathrm{C}$ and $\mathrm{Al}$ atoms ${ }^{5-12} \mathrm{It}$ is noteworthy that successful studies have since been reported by other groups. State-resolved differential cross sections have thus been obtained for the reaction $\mathrm{D}+\mathrm{H}_{2} \rightarrow \mathrm{HD}+\mathrm{H}$ : the high potential energy barrier being overcome by the kinetic energy mainly due to the fast $\mathrm{D}$ atoms $(2.2 \mathrm{eV}$ in the laboratory frame) generated by ArF photolysis of $\mathrm{D}_{2} \mathrm{~S}$ in the collisionless region. ${ }^{13}$ The excitation function and the product state distribution have also been found for another isotopic exchange reaction: $\mathrm{CH}+\mathrm{D}_{2} \rightarrow \mathrm{CD}+\mathrm{HD}$, the supercooled $\mathrm{CH}\left({ }^{2} \pi_{1 / 2}, v^{\prime \prime}=0\right.$, $N^{\prime \prime}=1$ ) radicals being created by ArF laser-induced chemistry in the hydrodynamic region of expanding $\mathrm{CH}_{3} \mathrm{I} / \mathrm{Xe} / \mathrm{H}_{2}$ mixtures. ${ }^{14}$

\section{CROSSED BEAM EXPERIMENTS}

In our molecular beam experiments, reactions between ground-state atoms of more or less refractory elements and small oxidant molecules have been studied in the single collision regime, by crossing collimated, pulsed, supersonic molecular beams of short duration at right angles. Product quantum-state distributions and their collision energy dependence could be obtained by using pulsed laser-induced fluorescence (LIF) at the crossing point and by varying the velocity of the refractory atom beam. Such data can provide information about the nature of the potential energy hypersurface (PES) connecting reactants and products.

The present paper aims at describing some salient differences with the steady-state approach to such experiments. The first consists of the production of intense beams of atoms. The second one concerns data reduction to extract quantitative information from the spectra, which requires the solution of the problem of density-flux transformation. The last two features discussed hereafter result from the characteristics of our pulsed atom beam source, i.e. the significant increase in the signalto-background ratio, and the ability to scan a wide range of relative translational energy.

\section{Pulsed Atom Beam Source}

A schematic view of the experiment is given on Figure 1. As the apparatus has been the object of a recent paper describing all the experimental details, ${ }^{15}$ this section only relates the key points of the metal-atom beam source design.

The idea of the pulsed supersonic metal-atom beam came from the spectroscopy 


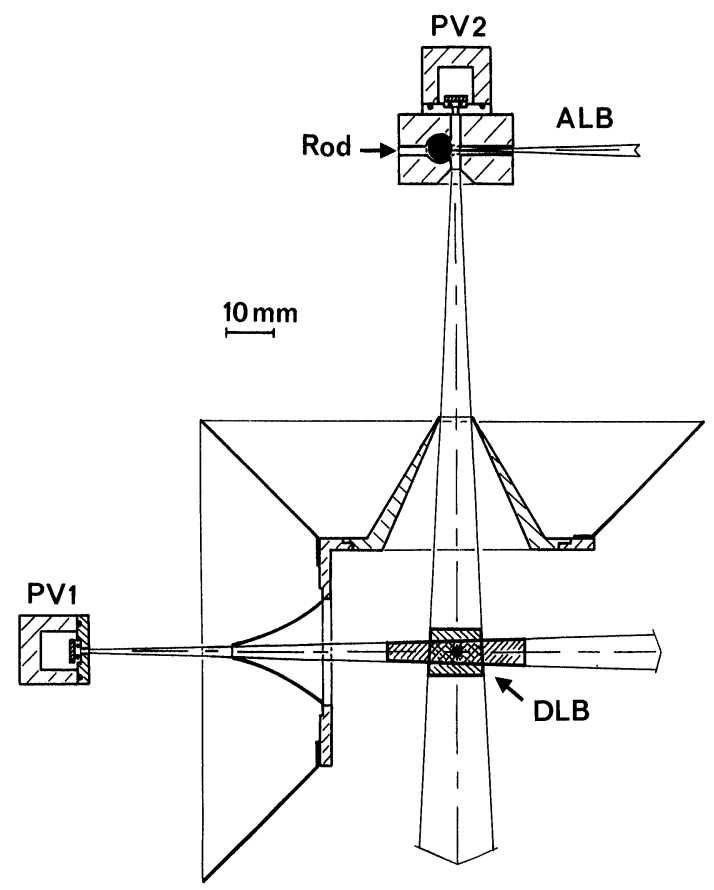

Figure 1 Schematic (cutaway through the molecular beam axis plane) of the experiment. The whole assembly is inside the vacuum chamber. PV1 and PV2: pulsed valves for the oxidiser beam and the metal-atom beam, ALB: ablation laser beam, DLB: dye laser beam. Typical density contours FWHM of the two molecular beams in the vicinity of the scattering centre at the probing time are shown.

experiments performed at Rice University on supersonic metal clusters. ${ }^{16,17}$ Laser ablation of a solid metal inside the throat of a pulsed nozzle using a pulsed laser (generally doubled Nd:Yag) was found so efficient and so promising that it literally induced an explosion of the metal cluster field. However, our own goal being to produce atom beams if possible free of any aggregates, the supersonic metal cluster source was redesigned for the production of monoatomic species.

In the supersonic metal cluster experiments cited above, optimum cluster growth for various elements such as $\mathrm{Cu}, \mathrm{Mo}, \mathrm{W}$ or $\mathrm{Nb}$ was found to occur by focussing 7-15 $\mathrm{mJ}$ in $6 \mathrm{~ns}$ pulses of $532 \mathrm{~nm}$ radiation $\left(2.33 \mathrm{eV}\right.$ or $\left.225 \mathrm{~kJ}^{\mathrm{mole}}{ }^{-1}\right)$ onto a $\phi 1.5 \mathrm{~mm}$ target resulting in fluences of $0.4-0.85 \times 10^{4} \mathrm{~J} \mathrm{~m}^{-2}$. Our own approach was to use higher photon energy together with higher fluence in order to induce complete dissociation of all the fragments ablated from the solid by multiphoton absorption. This was first achieved with spatially filtered radiation of a $\mathrm{KrF}$ laser operated with unstable resonator optics. Pulses of $248 \mathrm{~nm}$ radiation $\left(5 \mathrm{eV}\right.$, or $\left.482 \mathrm{~kJ}^{\text {mole }}{ }^{-1}\right)$ with the following characteristics: $7 \mathrm{~mJ}$ of energy within $1.2 \mathrm{mrad}$ and $15 \mathrm{~ns}$ full-width at half-maximum (FWHM), could be focussed onto the target as $0.4 \mathrm{~mm}$ spots, resulting in a fluence of $5.5 \times 10^{4} \mathrm{~J} \mathrm{~m}^{-2}$. Such a fluence, the highest that could be obtained with the type of laser used (Lambda Physik EMG 101 E with EMG 70 
unstable resonator), was very satisfactory for $\mathrm{Al}$ atom experiments but insufficient for some of the $\mathrm{C}$ atom studies. Indeed, unlike most of the other refractory elements, carbon gives small clusters having strong chemical bonds $\left(\mathrm{D}_{0}\left(\mathrm{C}_{2}\right)=6.21 \mathrm{eV}\right.$, $\mathrm{D}_{0}\left(\mathrm{C}_{3}\right)=7.31 \mathrm{eV}$ ) which perturb the system for two reasons. Firstly, $\mathrm{C}_{2}$ is an extremely reactive radical which could yield the same LIF detected product: a case study is the $\mathrm{C}+\mathrm{NO} \rightarrow \mathrm{CN}+\mathrm{O}$ system with the reaction $\mathrm{C}_{2}+\mathrm{NO} \rightarrow \mathrm{CN}+\mathrm{CO}$ occurring simultaneously. Secondly, $\mathrm{C}_{3}$ exhibits intense absorption bands $\left(\mathrm{A}^{1} \pi_{\mathrm{u}}-\mathrm{X}^{1} \Sigma_{\mathrm{g}}{ }^{+}\right.$transitions), extending throughout the ultra-violet and visible regions due to an unusually low bending mode $\left(63 \mathrm{~cm}^{-1}\right)$, which could blur out the LIF spectra of the scattered product. $\mathrm{C}_{2}$ and $\mathrm{C}_{3}$ densities in the carbon beam could be efficiently lowered in experiments performed up to ca. $20 \times 10^{4} \mathrm{~J} \mathrm{~m}^{-2}$ fluence using $7 \mathrm{~ns}$ pulses of $266 \mathrm{~nm}$ radiation delivered by a quadrupled Nd : Yag laser (Quantel SA YG585 with temperature phase-matched quadrupler). ${ }^{12}$

Following quasi-complete dissociation of the ablated species into atoms, cluster growth was limited by minimising three body recombination reactions. These collision processes occur in the sonic extension channel, between the vaporising point and the vacuum, and afterwards in the hydrodynamic region of the expansion of the carrier gas in vacuum. Cluster growth is therefore favoured by increasing the gas load of the pulsed valve and the extension-channel length. The supersonic cluster experiments at Rice were performed with a magnetically operated double-solenoid pulsed valve giving under typical conditions a total gas output of ca. $70 \mathrm{~mm}^{3}$ per pulse (normal pressure and temperature conditions) and a sonic channel length extending up to $30 \mathrm{~mm}$ after the vaporising point. In our metal-beam source, the Gentry and Giese $^{1}$ pulsed valve model used (Beam-Dynamics VCD-1) gave a gas load less than 20 times this value, and the sonic channel length was reduced to $3 \mathrm{~mm}$. These characteristics were nonetheless found to ensure efficient electronic quenching of the atom metastable states, reducing them to negligible amounts compared to the atom ground-state concentration. ${ }^{15}$ Any ions produced were easily removed from the beam with an electrostatic field.

\section{The Laboratory to Centre of Mass Transformation}

In crossed molecular beam experiments, the data obtained in the laboratory must be transposed in the centre-of-mass (CM) system before any interpretation of the results is made. This is common practice in reactive scattering experiments using an ionisation mass detector scanning the range of accessible laboratory angles: in general the laboratory intensity distribution is strongly weighted by those contributions which have low relative velocities. When LIF is performed at the beam crossing point, it yields laboratory quantum-state product densities which must also be transformed into fluxes in the $\mathrm{CM}$ frame. A simple density to flux conversion taking the recoil velocity vectors into account was introduced with the pioneering experiments in this field. ${ }^{18}$ Its application, however, requires the angular distribution to be known, which is generally not the case.

The simple transformation invoked above is also constrained to a limited domain of validity. It cannot be applied when performing experiments with pulsed beams of 
short physical length because a steady state is not reached when the LIF detection process is triggered. A misuse of this conversion also arises when experiments have been done with a laser beam not irradiating all the reaction zone but only its central part, which is very common in practice. In replacement, a mathematical model has been developed in our laboratory for reactive atom-diatomic systems. Product densities within the laser irradiated volume are calculated from the outcome of all the reactive events taking place in the beam overlap region up to the detection time. ${ }^{19}$ The model shows that the LIF detection efficiency can become extremely dependent not only on the internal energy state but also on the CM scattering angle. Moreover, changing the geometric arrangement of the experiment without changing the collision energy can drastically shift the maxima and minima of detection efficiency towards other values of the internal energy and recoil angle; in other words, for sharply peaked scattering angle distributions, the apparent rovibrational distributions of the excitation spectra can look totally different.

Typical results for the reaction:

$$
\mathrm{C}\left({ }^{3} \mathrm{P}_{\mathrm{J}}\right)+\mathrm{NO}\left(\mathrm{X}^{2} \pi_{\mathrm{r}}\right) \rightarrow \mathrm{CN}\left(\mathrm{X}^{2} \Sigma^{+}\right)+\mathrm{O}\left({ }^{3} \mathrm{P}_{\mathrm{J}}\right), \Delta \varepsilon_{0}=-1.27 \mathrm{eV}
$$

are displayed on the axonometric plots of Figure 2 which give the conversion function or LIF detection efficiency of the $\mathrm{CN}$ radical as a function of the CM recoil energy and the CM scattering angle. For example, point $\mathrm{A}$ on Figure $2 \mathrm{a}$ corresponds to radicals with no internal energy scattered forwards, point $B$ to radicals at the excitation limit (almost no recoil energy) scattered backwards. The product flux in any given internal energy state can be obtained when dividing the intensity of a corresponding LIF rovibrational line by the integral of the conversion function over the scattering angle distribution.

Effects of beam collimation and pulse duration are clearly seen on these plots. It is worth noting that operating conditions can be found where the LIF detection efficiency is almost independent of the scattering angle (Figure 2b), simply by selecting the diameters of the collimators, which is of great interest when the angular distribution is unknown. Gross features of the scattering can also be deduced by performing experiments with different collimators (Figures $2 a$ and $2 b$ ), the LIF signal behaving differently in the case of forward, backward or symmetric scattering. While these possibilities exist with pulsed, supersonic beam sources because the size and location of skimmers, which essentially act as collimators, are not critical parameters due to the absence of shock structure, ${ }^{4}$ they are, however, unrealistic in continuous beam experiments. The latter experiments can also have the drawback of giving very peculiar figures of the LIF detection efficiency (Figure 2c), unsuitable for correct determination of the internal energy partitioning. Such a very unfavourable case as in Figure 2c cannot be found using even mildly collimated pulsed beams of short duration because the overlap (both in space and time) of the beams away from the scattering centre is limited.

\section{The Obtention of High Signal-to-Background Ratios}

The signal-to-background ratio problem, which remains the major limitation in 

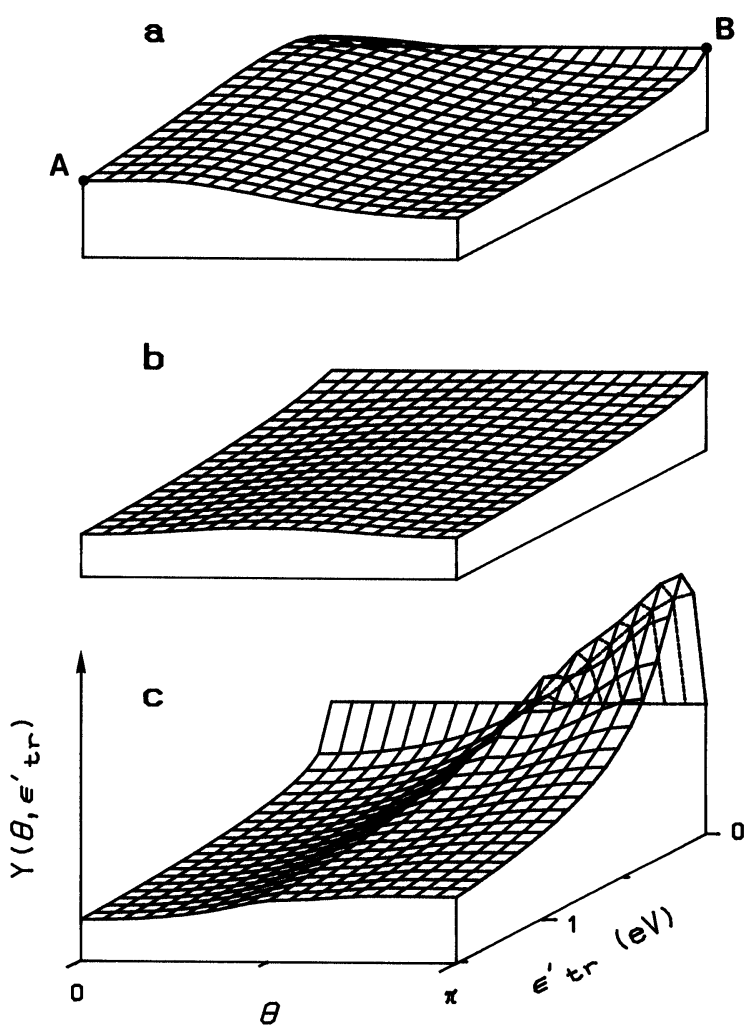

Figure 2 Conversion function or LIF detection efficiency $\mathrm{Y}\left(\varepsilon_{\mathrm{tr}}^{\prime}, \theta\right): \mathrm{z}$ axis, versus CM recoil energy $\varepsilon_{\mathrm{tr}}^{\prime}: \mathrm{y}$ axis and $\mathrm{CM}$ scattering angle $\theta$ : $\mathrm{x}$ axis, of the $\mathrm{CN}\left(\mathrm{X}^{2} \Sigma^{+}\right)$product from the $\mathrm{C}\left({ }^{3} \mathrm{P}_{\mathrm{J}}\right)+\mathrm{NO}\left(\mathrm{X}^{2} \pi_{\mathrm{r}}\right)$ reaction at $\varepsilon_{\mathrm{tr}}=0.234 \mathrm{eV}$ (beam velocities: $\mathrm{v}_{\mathrm{c}}=2140 \mathrm{~ms}^{-1}$ and $\mathrm{v}_{\mathrm{NO}}=830 \mathrm{~ms}^{-1}$ ), in the case of a laser beam irradiating the central part of the collision volume. a: pulse durations FWHM: $\delta \mathrm{t}_{\mathrm{c}}=4.3 \mu \mathrm{s}$ and $\delta \mathrm{t}_{\mathrm{NO}}=35$ $\mu$ s, beam diameters FWHM at the collision zone: $d_{c}=17 \mathrm{~mm}$ and $d_{N O}=14 \mathrm{~mm}$; b: same as a except $\mathrm{d}_{\mathrm{NO}}=6 \mathrm{~mm} ; \mathrm{c}: \delta \mathrm{t}_{\mathrm{c}}$ and $\delta \mathrm{t}_{\mathrm{NO}} \rightarrow \infty, \mathrm{d}_{\mathrm{c}}=17 \mathrm{~mm}$ and $\mathrm{d}_{\mathrm{NO}}=6 \mathrm{~mm}$.

molecular beam scattering experiments, is well illustrated with the case of the reaction:

$$
\mathrm{C}\left({ }^{3} \mathrm{P}_{\mathrm{J}}\right)+\mathrm{N}_{2} \mathrm{O}\left(\mathrm{X}^{1} \Sigma^{+}\right) \rightarrow \mathrm{CN}\left(\mathrm{X}^{2} \Sigma^{+}\right)+\mathrm{NO}\left(\mathrm{X}^{2} \pi_{\mathrm{r}}\right), \Delta \varepsilon_{0}=-2.78 \mathrm{eV}
$$

Carbon is one of the most refractory elements and obtaining a carbon beam with a metal-oven effusive source can only be achieved by operating the oven at an extremely high temperature (up to $3500 \mathrm{~K}$ ) ${ }^{20}$ At such a temperature, the effusive carbon beam contains roughly equal amounts of $\mathrm{C}, \mathrm{C}_{2}$ and $\mathrm{C}_{3}$ species. On the one hand, complete time-of-flight discrimination of these species, which have different velocity distributions, by using a multiple chopper-disk velocity selector is hardly conceivable without loosing most of the $\mathrm{C}$ flux. On the other hand, leaving a small fraction of the highly rovibrationally excited $\mathrm{C}_{3}$ radical in the $\mathrm{C}\left({ }^{3} \mathrm{P}_{\mathrm{J}}\right)$ beam, would result in a background LIF signal throughout the whole spectral region of the $\mathrm{CN}$ 
violet system. Such an effusive source is therefore poorly suited to reaction dynamics studies using LIF detection.

CN LIF spectra previously obtained in the early stages of development of our apparatus were not completely free of $\mathrm{C}_{3}$ lines. ${ }^{6-7}$ This problem was finally solved as stressed above by increasing the fluence used for the laser ablation of graphite. The $\mathrm{CN}\left(\mathrm{X}^{2} \Sigma^{+}\right)$excitation spectrum of Figure $3 \mathrm{a}$, obtained this time at larger nozzlecrossing point distances and with beams collimated to $10^{\circ} \mathrm{FWHM}$, has a larger signal-to-noise ratio and therefore contains dynamical informations of higher quality. The high rovibrational excitation results in prominent bandheads up to $v^{\prime \prime}=6$. The (6-7) band is not clearly observed although it should also exhibit a head in the vicinity of the (5-6) one. However, due to the spectral congestion in this region, it is difficult to ascertain whether the rovibrational manifold is populated above $v^{\prime \prime}>6$ or not. Synthetic spectra ${ }^{12}$ in fair agreement with the experimental one could be obtained by including a vibrational distribution only up to $v^{\prime \prime}=6$ (Figure $3 \mathrm{~b}$ and $3 \mathrm{c}$ ).

It must be stressed at this level that the relative translational energy for a given $\mathrm{CN}$ quantum-state is not as well defined as in the $\mathrm{C}+\mathrm{NO} \rightarrow \mathrm{CN}+\mathrm{O}$ reaction. It can, rather, take any discrete value allowed by the energy conservation law, depending upon the partitioning of the remaining available energy between fragment relative translation and NO internal degrees of freedom. As a consequence, some assumptions are needed to compute the CN LIF detection efficiency. Synthetic spectra have thus been computed assuming either similar internal energy distributions for $\mathrm{CN}$ and NO, or no NO internal energy at all (Figures $3 b$ and 3c, respectively).

The following dynamical trends, independent of the hypotheses, can be derived from the inspection of the spectra of Figure 3. The rotational excitation is high: the distributions are definitely non-Boltzmann; however, the mean energies correspond to "rotational temperatures" as high as $11000 \mathrm{~K}$ for $\mathrm{CN}\left(v^{\prime \prime}=1\right)$. The $\mathrm{CN}$ vibrational distribution is bell shaped, peaking at $v^{\prime \prime}=3$ and exhibiting a sharp drop for $v^{\prime \prime}>6$. This apparent excitation limit, roughly at half the total energy available to the products, strongly suggest that an important fraction of the reaction energy is deposited in NO. Such behaviour is consistent with the existence of a deep well in the $\mathrm{PES}^{21}$ which may favour a balanced energy partitioning between two vibrating rotators having almost identical vibrational and rotational constants.

\section{The Variation of the Relative Translational Energy}

The possibility of scanning the collision energy over a wide range of relative translational energies is another specification of a crossed pulsed supersonic beam apparatus. A study of the reaction:

$$
\operatorname{Mg}\left({ }^{1} \mathrm{~S}_{0}\right)+\mathrm{N}_{2} \mathrm{O}\left(\mathrm{X}^{1} \Sigma^{+}\right) \rightarrow \mathrm{MgO}\left(\mathrm{X}^{1} \Sigma^{+}\right)+\mathrm{N}_{2}\left(\mathrm{X}^{1} \Sigma_{\mathrm{g}}^{+}\right), \Delta \varepsilon_{0} \approx-1.5 \mathrm{eV},
$$

presently in progress illustrates its use.

Previous works by several groups have always remained at a qualitative level. The reaction was not observed with a Broida-type apparatus at $300 \mathrm{~K} .{ }^{22}$ LIF detection of $\operatorname{MgO}\left(\mathrm{X}^{1} \Sigma^{+}\right)$failed at a first attempt in beam-gas configuration with a magnesiumoven effusive source operated at $1400 \mathrm{~K}$ and the scattering gas at $300 \mathrm{~K}$ but succeeded 


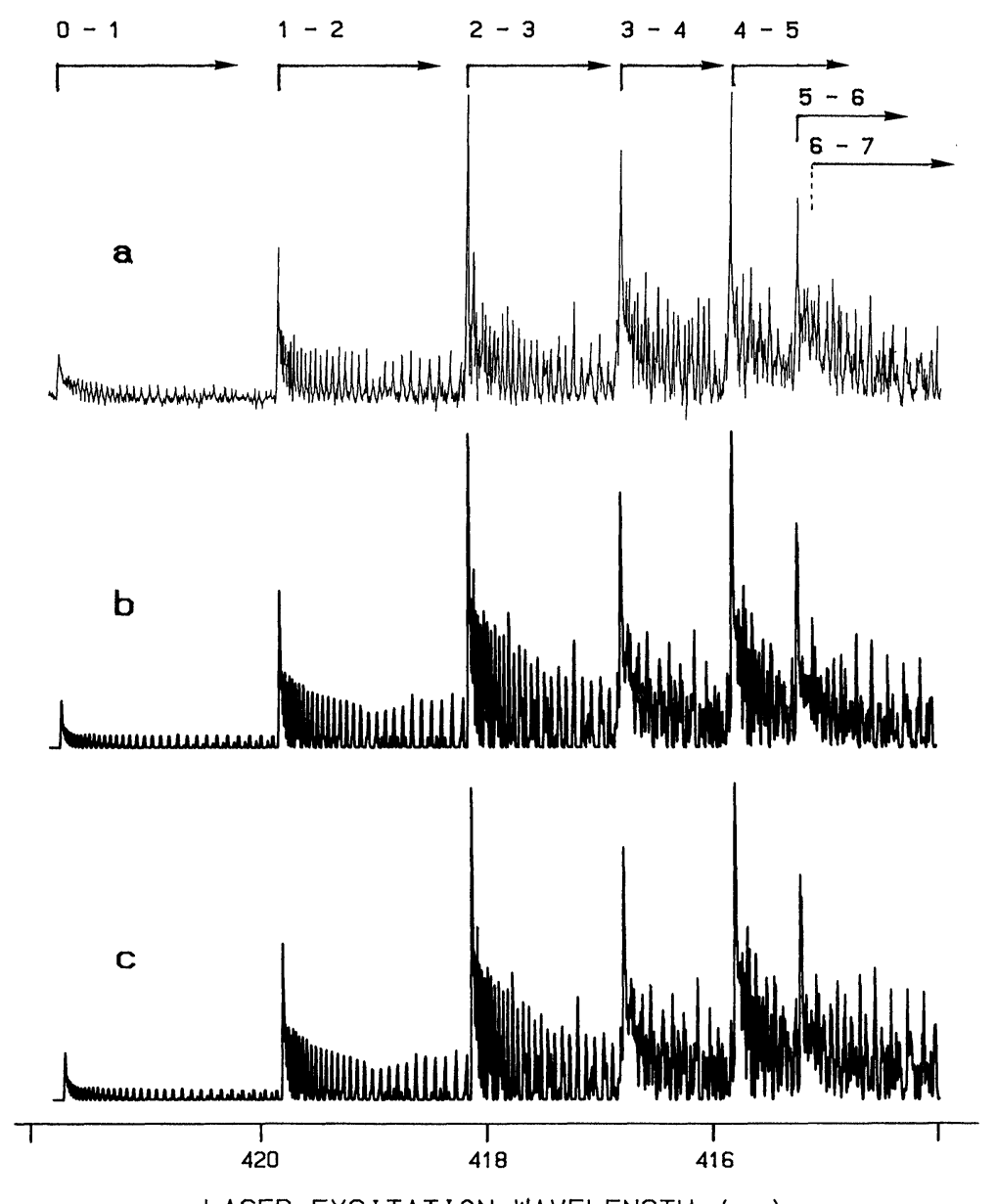

LASER EXCITATION WAVELENGJH $(\mathrm{nm})$

Figure 3 LIF spectrum of $\mathrm{CN}\left(\mathrm{X}^{2} \Sigma^{+}\right)$product from the $\mathrm{C}\left({ }^{3} \mathrm{P}_{\mathrm{J}}\right)+\mathrm{N}_{2} \mathrm{O}\left(\mathrm{X}^{1} \Sigma^{+}\right)$reaction at $0.28 \mathrm{eV}$ relative translational energy. $\mathrm{CN}\left(\mathrm{B}^{2} \Sigma^{+}-\mathrm{X}^{2} \Sigma^{+}\right)$transition, $\Delta v=-1$ sequence; $v^{\prime}-v^{\prime \prime}$ : vibronic assignment. a: experimental spectrum, $\mathrm{b}$ : synthetic spectrum computed when assuming similar internal distributions for $\mathrm{CN}$ and $\mathrm{NO}$, with the following relative vibrational populations, $\mathrm{N}_{v^{\prime \prime}}=0.26,0.67,1.00,0.66,0.57,0.28$ for $v^{\prime \prime}=1-6$, respectively, c: synthetic spectrum computed when assuming no NO internal energy, with $\mathrm{N}_{v^{\prime \prime}}=0.21,0.60,1.00,0.75,0.74,0.27$ for $v^{\prime \prime}=1-6$, respectively.

in a second experiment due to an improved detection sensitivity. ${ }^{23-24}$ Successful LIF detection was also reported in a flow experiment at $520 \mathrm{~K}$ but no spectrum was published. ${ }^{25}$ Finally $\mathrm{MgO}\left(\mathrm{X}^{1} \Sigma^{+}\right)$LIF was obtained with high signal-to-noise ratio by mixing $\mathrm{Mg}$ vapor from an oven at $1100 \mathrm{~K}$ with $\mathrm{N}_{2} \mathrm{O}$ preheated at this temperature. ${ }^{26}$ Clearly, the apparent increase of reactivity with collision energy of the $\operatorname{Mg}\left({ }^{1} \mathrm{~S}_{0}\right)+$ $\mathrm{N}_{2} \mathrm{O}$ system can be ascribed to the presence of a high potential energy barrier in the entrance channel of the ground-state PES which has been predicted by ab initio calculations. ${ }^{27}$ 


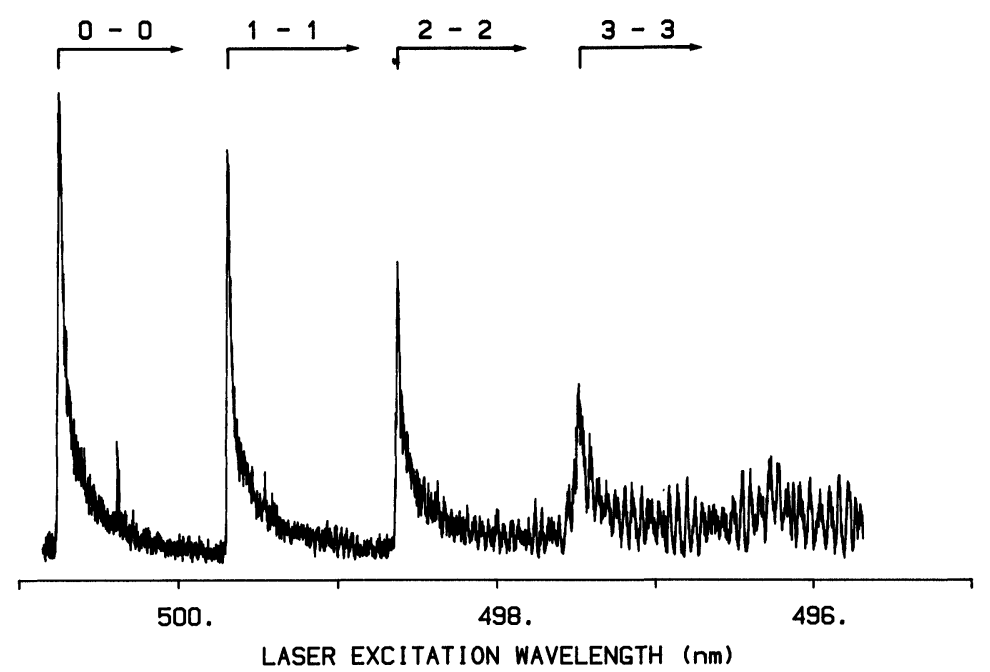

Figure 4 LIF spectrum of $\mathrm{MgO}\left(\mathrm{X}^{1} \Sigma^{+}\right)$product from the $\mathrm{Mg}\left({ }^{1} \mathrm{~S}_{0}\right)+\mathrm{N}_{2} \mathrm{O}\left(\mathrm{X}^{1} \Sigma^{+}\right)$reaction at $0.9 \mathrm{eV}$ relative translational energy. $\mathrm{MgO}\left(\mathrm{B}^{1} \Sigma^{+}-\mathrm{X}^{1} \Sigma^{+}\right)$transition, $\Delta v=0$ sequence; $v^{\prime}-v^{\prime \prime}$ : vibronic assignment.

An excitation spectrum of the $\mathrm{MgO}\left(\mathrm{X}^{1} \Sigma^{+}\right)$product taken at $\varepsilon_{\mathrm{tr}}=0.9 \mathrm{eV}$ is presented on Figure 4. Several experiments were performed at a set of lower values of $\varepsilon_{\mathrm{tr}}$ obtained by varying the velocity of the $\mathrm{Mg}$ beam, keeping constant conditions on the $\mathrm{N}_{2} \mathrm{O}$ beam, and recording alternatively the LIF intensities of the $\mathrm{MgO}(0-0)$ bandhead and of the $\operatorname{Mg}\left({ }^{1} \mathrm{P}_{1}-{ }^{1} \mathrm{~S}_{0}\right)$ resonance transition at $285.21 \mathrm{~nm}$. The variation of the relative reactive cross section with collision energy could thus be extracted with the assumption that the internal energy partitioning and the angular distribution of the $\mathrm{MgO}$ product did not change markedly in this energy range. First, quantitative

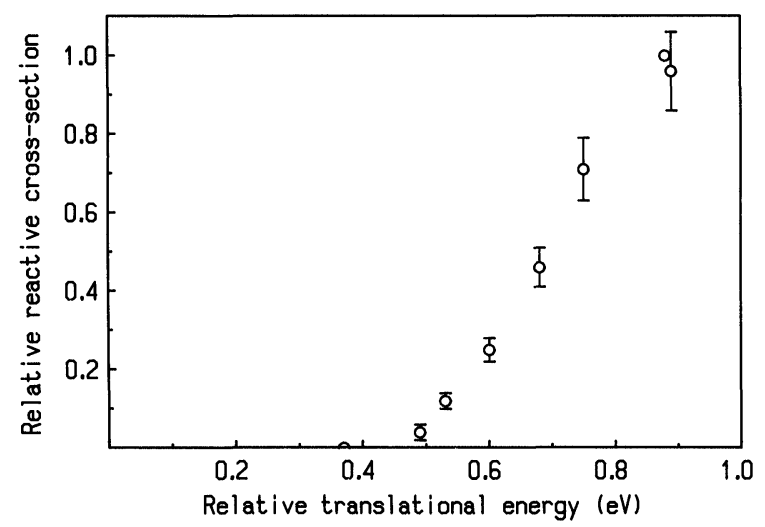

Figure 5 Relative reactive cross-section of the $\mathrm{Mg}\left({ }^{1} \mathrm{~S}_{0}\right)+\mathrm{N}_{2} \mathrm{O} \rightarrow \mathrm{MgO}\left(\mathrm{X}^{1} \Sigma^{+}\right)+\mathrm{N}_{2}\left(\mathrm{X}^{1} \Sigma_{\mathrm{g}}{ }^{+}\right)$product channel, as a function of the relative translational energy. 
dynamical information on the reaction is shown with the excitation function (Figure 5) which exhibits a sharp threshold near $\varepsilon_{\mathrm{tr}}=0.5 \mathrm{eV}$. This translational energy threshold represents an upper limit of the energy barrier located on the entrance channel of the PES.

\section{Acknowledgements}

The authors wish to thank Professor J. Joussot-Dubien for his constant interest in this work.

\section{References}

1. W. R. Gentry and C. F. Giese, Rev. Sci. Instrum. 49, 595 (1978).

2. W. R. Gentry, Comm. At. Mol. Phys. 9, 113 (1980).

3. W. R. Gentry, in Electronic and Atomic Collisions, eds. N. Noda and N. Takayanagi, North Holland, Amsterdam, 1980, p. 807.

4. W. R. Gentry, in Atomic and Molecular Beam Methods, ed. G. Scoles, Oxford University Press, New York, 1988, p. 54.

5. G. Dorthe, M. Costes, C. Naulin, C. Vaucamps, G. Nouchi and J. Joussot-Dubien, C. R. Acad. Sci. Paris II 301, 9 (1985).

6. G. Dorthe, M. Costes, C. Naulin, J. Joussot-Dubien, C. Vaucamps and G. Nouchi, J. Chem. Phys. 83, $3171(1985)$

7. M. Costes, G. Dorthe, B. Duguay, P. Halvick, J. Joussot-Dubien, C. Naulin, G. Nouchi, J. C. Rayez, M. T. Rayez and C. Vaucamps, in Recent Advances in Molecular Reaction Dynamics, eds. R. Vetter and J. Vigué, Editions du CNRS, Paris, 1986, p. 97.

8. M. Costes, C. Naulin, G. Dorthe, J. Marchais and C. Vaucamps, C.R. Acad. Sci. Paris II 303, 1279 (1986).

9. M. Costes, C. Naulin, G. Dorthe, C. Vaucamps and G. Nouchi, Faraday Discuss. Chem. Soc. 84, 75 (1987).

10. M. Costes, C. Naulin, G. Dorthe and G. Nouchi, in Selectivity in Chemical Reactions, ed. J. C. Whitehead, Kluwer Academic Publishers, Dordrecht, NATO ASI Series C245, 105 (1988).

11. C. Naulin, M. Costes, G. Dorthe and P. Caubet, J. Chem. Soc. Faraday Trans, 86, 887 (1990).

12. M. Costes, C. Naulin and G. Dorthe, Astron. Astrophys. (1990) in press.

13. S. A. Buntin, C. F. Giese and W. R. Gentry, J. Chem. Phys. 87, 1443 (1987).

14. K. Liu and R. G. Macdonald, J. Chem. Phys. 89, 4443 (1988).

15. M. Costes, C. Naulin, G. Dorthe, G. Daleau, J. Joussot-Dubien, C. LaLaude, M. Vinckert, A. Destor, C. Vaucamps and G. Nouchi, J. Phys. E: Sci. Instrum. 22, 1017 (1989).

16. J. B. Hopkins, P. R. R. Langridge-Smith, M. D. Morse and R. E. Smalley, J. Chem. Phys. 78, 1627 (1983).

17. D. E. Powers, S. G. Hansen, M. E. Geusic, D. L. Michalopoulos and R. E. Smalley, J. Chem. Phys. 78, 2866 (1983).

18. H. W. Cruse, P. J. Dagdigian and R. N. Zare, Faraday Discuss. Chem. Soc. 55, 277 (1973).

19. C. Naulin, M. Costes, A. Benseddik and G. Dorthe, Laser Chem. 8, 283 (1988).

20. H. F. Krause, Chem. Phys. Letters 78, 78 (1981).

21. J. C. Rayez, M. T. Rayez and B. Duguay, J. Chem. Phys. 78, 827 (1983).

22. B. Bourguigon, J. Rostas and G. Taieb, J. Chem. Phys. 77, 2979 (1982).

23. P. J. Dagdigian, J. Chem. Phys. 76, 5375 (1982).

24. J. W. Cox and P. J. Dagdigian, J. Phys. Chem. 88, 2455 (1984).

25. W. H. Breckenridge and H. Umemoto, J. Phys. Chem. 87, 1804 (1983).

26. H. Büsener, F. Heinrich and A. Hese, Chem. Phys. 112, 139 (1987).

27. D. R. Yarkony, J. Chem. Phys. 78, 6763 (1983). 